Notes

\title{
Determination of Barium Ions in River-Water Samples by Inductively Coupled Plasma-Atomic Emission Spectrometry after Preconcentration by Solvent Extraction
}

\author{
Koji Yamagaki, Michinao YoshiI and Keio Yamada \\ Water Quality Management Section, Niigata Municipal Bureau of Water Works, \\ Aoyamasuido, Nïgata 950-21, Japan
}

Keywords Solvent extraction, inductively coupled plasma-atomic emission spectrometry, barium ion, river water

The maximum cotaminant level (MCL) for barium $\left(1 \mathrm{mg} \mathrm{l}^{-1}\right)$ has been established in the national interim primary drinking water regulations. Soluble barium salts are known to be toxic when ingested into the body or when external exposure occurs.

The extractions of barium with hexafluoroacetylacetone ${ }^{1}, 18$-crown- $6^{2}$, and polyethylene glycol ${ }^{3}$ have been reported.

The present authors studied a method based on solvent extraction with 2-thenoyltrifluoroacetone ${ }^{4}$ (abbreviated as TTA) and subsequent inductively coupled plasmaatomic emission spectrometry (ICP-AES) of barium. TTA is available at a reasonable cost, and the extraction procedure with TTA is simple. Barium was quantitatively extracted with $0.5 \mathrm{M}$ TTA in MIBK from a solution adjusted to $\mathrm{pH} 10.0$ with $\mathrm{NH}_{4} \mathrm{OH}$. Then $0.2 \mathrm{M}$ hydrochloric acid was added and barium ions were back-extracted. The aqueous phase was injected into the ICP. The present method has been applied to the determination of barium in river-water samples.

\section{Experimental}

\section{Reagents}

Standard barium solution. A standard solution (1 mg $\mathrm{ml}^{-1}$ ) of barium was prepared by dissolving $1.523 \mathrm{~g}$ of reagent-grade barium chloride, anhydrous in $1 \mathrm{M}$ hydrochloric acid.

TTA solution. A TTA solution $(0.5 \mathrm{M})$ was prepared by dissolving TTA (Dojindo Laboratories) in 4-methyl-2pentanone (MIBK).

All of the other reagents were of analytical reagent grade.

\section{Apparatus}

An inductively coupled plasma atomic emission spectrometer (Shimadzu ICPQ-100) was used. The RFpower was supplied with a built-in $27.12 \mathrm{MHz}$ generator. The ICP conditions are listed in Table 1.
Table 1 Operating conditions for ICP-AES

\begin{tabular}{ll} 
Power & $1.2 \mathrm{~kW}$ \\
Ar flow rate & $10.5 \mathrm{l} / \mathrm{min}$ (coolant) \\
& $1.51 / \mathrm{min}$ (plasma) \\
& $1.0 \mathrm{l} / \mathrm{min}$ (carrier) \\
Observation height & $15 \mathrm{~mm}$ above the load coil \\
Integration time & $20 \mathrm{~s}$ \\
Analytical line & $\mathrm{Ba} 455.4 \mathrm{~nm}$ \\
\hline
\end{tabular}

pH meter: a pH meter, Model M-7 Horiba Manufacturing $\mathrm{Co}$., was employed.

\section{Experimental procedure}

Each test sample of $100 \mathrm{ml}$ was adjusted to $\mathrm{pH} 10.0$ with $7 \mathrm{M} \mathrm{NH} \mathrm{NH}_{4} \mathrm{OH}$. In a separatory funnel, $10 \mathrm{ml}$ of a $0.5 \mathrm{M}$ TTA MIBK solution and $100 \mathrm{ml}$ of a sample solution were mixed. The funnel was then shaken for 10 min with an electric shaker. After the two phases had separated, the aqueous solution was extracted. The organic phase remaining in the funnel was treated with $10 \mathrm{ml}$ of $0.2 \mathrm{M}$ hydrochloric acid in order to back-extract the barium ions in the organic phase. The concentration of barium back-extracted into the hydrochloric solution was determined by ICP-AES.

\section{Results and Discussion}

\section{Effect of diluents}

MIBK and benzene were tested as diluents. The recovery of barium at $\mathrm{pH} 10.0$ was $94 \%$ and $2.2 \%$ with MIBK and benzene, respectively. Hence, MIBK was preferred as the diluent.

\section{Effect of TTA concentration}

Barium was extracted at pH 10.0 with $10 \mathrm{ml}$ of $0.5 \mathrm{M}$ TTA in MIBK. Because the recovery of barium was $46.6,92.5,93,93$ and $93 \%$ with $0.01,0.05,0.1,0.2$ and 
Table 2 Recovery of metals in solvent extraction

\begin{tabular}{lcccccc}
\hline \multirow{2}{*}{ Ion } & \multirow{2}{*}{ Added $/ \mathrm{mg} \mathrm{l}^{-1}$} & Found $/ \mathrm{mg} \mathrm{l}^{-1}$ & Recovery, $\%$ & & \multicolumn{2}{c}{ Ba $/ \mathrm{mg} \mathrm{l}^{-1}$} \\
\cline { 6 - 7 } & & & & Added & Found & Recovery, \% \\
\hline $\mathrm{Mg}$ & 5 & 3.1 & 62 & 0.1 & 0.096 & 96 \\
$\mathrm{Ca}$ & 20 & 8.2 & 41 & 0.1 & 0.093 & 93 \\
$\mathrm{Na}$ & 10 & 0.6 & 6 & 0.1 & 0.095 & 95 \\
$\mathrm{Al}$ & 2 & 0.04 & 75 & 0.1 & 0.093 & 93 \\
$\mathrm{Fe}$ & 2 & 1.5 & 3 & 0.1 & 0.098 & 98 \\
$\mathrm{~K}$ & 2 & 0.06 & 0.1 & 0.095 & 95 \\
\hline
\end{tabular}

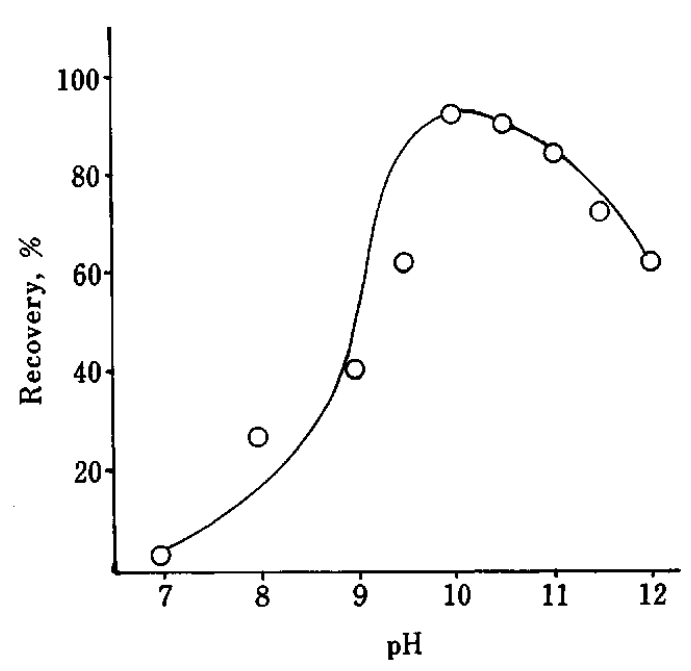

Fig. 1 Effect of pH on recovery of barium. Sample, $100 \mathrm{ml}$ (Ba $0.1 \mathrm{mg} / \mathrm{l}$ ); $0.5 \mathrm{M}$ TTA MIBK solution, $10 \mathrm{ml} ; 0.2 \mathrm{M} \mathrm{HCl}$, $10 \mathrm{ml}$.

\section{$0.5 \mathrm{M}$ TTA respectively.}

\section{Effect of $\mathrm{pH}$ on the recovery of barium}

Measure out $100 \mathrm{ml}$ of the sample containing $0.1 \mathrm{mg}$ barium into a quartz beaker and adjust each $\mathrm{pH}$ to the 7-12 range. Transfer each solution to a funnel and treat as described above. From Fig. 1 the optimum pH for the recovery of barium was 10.0 .

\section{Co-extracted ions}

Alkali and alkaline earth elements, iron and aluminum, were co-extracted with barium (Table 2 ).

\section{Effect of diverse ions on the determination of barium}

For the purpose of applying the present method to the determination of barium in river-water samples, the interfering effect of various metal ions on the determination was studied. Barium of $0.1 \mu \mathrm{g} \mathrm{ml}^{-1}$ was extracted from a solution containing various metal ions by the above-mentioned method. The amount of metal ions added was approximately fifty-times that of the river-water sample. Magnesium, sodium, aluminum, iron, and potassium were tolerated at a ratio of $1: 1000$, $1: 5000,1: 500,1: 500$, and $1: 500$, respectively, as shown in Table 3. However, although calcium ions had an influence of $18 \%$ on the determination of barium at a
Table 3 Effect of coexisting ions on the determination of barium

\begin{tabular}{lccc}
\hline \multirow{2}{*}{ Ion } & \multirow{2}{*}{ Added $/ \mathrm{mg} \mathrm{l}^{-1}$} & \multicolumn{2}{c}{$\mathrm{Ba} / \mathrm{mg} \mathrm{l}^{-1}$} \\
\cline { 3 - 4 } & & Added & Found \\
\hline $\mathrm{Mg}$ & 100 & 0.1 & 0.106 \\
$\mathrm{Ca}$ & 500 & 0.1 & 0.118 \\
$\mathrm{Na}$ & 500 & 0.1 & 0.100 \\
$\mathrm{Al}$ & 50 & 0.1 & 0.106 \\
$\mathrm{Fe}$ & 50 & 0.1 & 0.106 \\
$\mathrm{~K}$ & 50 & 0.1 & 0.103 \\
\hline
\end{tabular}

Table 4 Analytical results for barium in river-water samples

\begin{tabular}{ccc}
\hline Added $/ \mathrm{mg} \mathrm{l}^{-1}$ & Found $/ \mathrm{mg} \mathrm{l}^{-1}$ & Recovery, \% \\
\hline 0 & 0.010 & $-(n=3)$ \\
0.1 & 0.102 & $92(n=5)$ \\
\hline
\end{tabular}

Sample was taken from Shinano River, Niigata City.

Sample: $100 \mathrm{ml}$.

ratio of $1: 5000$, calcium ions were extracted at only $40 \%$ and the concentration of the calcium ions in water was about $10 \mathrm{mg} \mathrm{l}^{-1}$, calcium was tolerated at a ratio $1: 500$.

\section{Analysis of the environmental sample}

After filtering, we added known amounts of barium to river-water samples and measured the recovery of barium according to the previously outlined procedure. The analytical results are given in Table 4 . The recovery of barium by this method was $92 \%$ and the relative standard deviation was $4.7 \%$. The detection limit was $0.0006 \mathrm{mg}$ $\mathrm{i}^{-1}$ according to the expression $\left\{3 \times \sigma_{\mathrm{B}} \times C /\left(\bar{X}_{\mathrm{S}}-\bar{X}_{\mathrm{B}}\right)\right\}$, where $C$ is the concentration of barium, $\bar{X}_{\mathrm{S}}$ is the mean emission intensity of the sample, and $\bar{X}_{B}$ is the mean emission intensity of the blank.

\section{References}

1. L. Edelbec, P. W. West, Anal. Chim. Acta, 52, 447 (1970).

2. Y. Takeda, Bull. Chem. Soc. Jpn., 52, 2501 (1979).

3. A. M. Y. Jaber, M. Y. S. El-Issa, Analyst [London], 106, 939 (1981).

4. I. Akaza, Bull. Chem. Soc. Jpn., 39, 971 (1966).

(Received September 27, 1992) (Accepted March 10, 1993) 